\title{
Complete Hydatiform Mole Revealed by a Severe Preeclampsia on Added in a 39-Year-Old Pregnant: Report of a Case Followed in Kisangani (DRC) and Review of the Literature
}

\author{
J. D. Bosenge Nguma*, O. N. Labama, A. J. Nadi, O. A. Modia, B. G. Katenga, L. E. Komanda \\ Department of Gynecology-Obstetrics, Faculty of Medicine and Pharmacy, Kisangani University, Kisangani, DRC \\ Email: *jdidier.bosenge@unikis.ac.cd
}

How to cite this paper: Bosenge Nguma, J.D., Labama, O.N., Nadi, A.J., Modia, O.A., Katenga, B.G. and Komanda, L.E. (2018) Complete Hydatiform Mole Revealed by a Severe Preeclampsia on Added in a 39-Year-Old Pregnant: Report of a Case Followed in Kisangani (DRC) and Review of the Literature. Open Journal of Obstetrics and Gynecology, 8, 505-512. https://doi.org/10.4236/ojog.2018.85057

Received: March 10, 2018

Accepted: May 14, 2018

Published: May 17, 2018

Copyright $\odot 2018$ by authors and Scientific Research Publishing Inc. This work is licensed under the Creative Commons Attribution International License (CC BY 4.0).

http://creativecommons.org/licenses/by/4.0/

\section{c) (i) Open Access}

\begin{abstract}
The classic picture of a hydatiform mole is made of recurrent metrorrhagia, exaggeration of sympathetic signs, increase of uterine volume compared to gestational age and marked elevation of serum $\beta$-hCG. The occurrence of preeclampsia is less common and its mechanism is less well known. In this case, the authors report an atypical presentation of the complete hydatiform mole alarmed by chronic hypertension with preeclampsia added to a pregnant woman of 39 years. The management involved stopping the pregnancy and normalization of the blood pressure figures was spectacular after uterine aspiration.
\end{abstract}

\section{Keywords}

Hydatiform Mole, Preeclampsia, $\beta$-hCG, Kisangani, DRC

\section{Introduction}

Hydatiform mole (HM) is a trophoblastic disease characterized by polycystic and hydropic degeneration of some or all of the chorionic villi. It is a benign entity but whose identification matters for two reasons: it can evolve towards clinically malignant entities, and the classifications of trophoblastic neoplasia that determine the therapeutic management take into account the type of initial gestation [1].

$\mathrm{HM}$ can be categorized as complete mole (CHM) and partial mole (PHM) dis- 
similar by epidemiology, clinical presentation, anatomopathology and genetics. The diagnosis of HM has now become easy thanks to the advent of ultrasound and the quantitative determination of $\beta$-hCG. Nevertheless, the clinical picture associating recurrent genital bleeding and exaggeration of the sympathetic signs of pregnancy (nausea and vomiting) with increase of the uterine volume compared to the gestational age, is usually conventional when it comes to a CHM. The occurrence of early preeclampsia (before 20 weeks of amenorrhea) on HM is a rare situation, but is usually encountered in cases of type I triploidy with partial mole. Those pregnancies with triploidy rarely evolve until the second trimester; once this period is reached, a high risk of early preeclampsia is often noted [2].

In the series of Rijhsinghani et al. [3], of 17 pregnancies with triploidy, 6 (35\%) had developed early preeclampsia or chronic high blood pressure (CHBP).

Early preeclampsia in case of CHM is a rare event, recorded in about $5 \%$ of cases and less clear mechanism [4].

We report the case of a CHM alarmed by $\mathrm{CHBP}$ with severe preeclampsia on added to a 39-year-old pregnant, whose evolution of blood pressure was spectacular after aspirational curettage of the product design. We will remind clinic of an illness and pathogeny of various signs.

\section{Case Presentation}

A pregnant woman 39 years old, P2G3A0, with no history of diabetes, nor high blood pressure (HBP), was transferred from a peripheral health center for HBP on pregnancy of 14 weeks (WA) and 4 days. About 2 weeks before, she complained of metrorrhagia of the first and heavy vomiting treated with antispasmodics and antiemetics without improvement. A few days later, this clinical picture was enriched by headache, progressive pelvic pain and severe physical asthenia; the vomiting became more and more important and the blood pressure was 190/110 mmHg, reason for its transfer to the University Clinics of Kisangani (UCK).

At admission to the UCK she had a pained look, the palpebral conjunctiva were pale; the BP of 190/115 mmHg. The uterine fund us was palpated $3 \mathrm{~cm}$ below the umbilicus; the cervix admitted the finger pulp, with endo-uterine bleeding. The lower segment was bulging, without fetal sluggishness; there was bilateral soft peri-malleolar edema. Ultrasound was used to objectify characteristic honeycomb or snowflake images filling the entire uterine cavity (Figure 1) and bilateral luteal cysts.

The biological assessment showed a hypochromic microcytic anemia associated with a biological hyperthyroidism and a serum beta-hCG level quantified at $12,800 \mathrm{mIU} / \mathrm{ml}$. The pregnant woman was of the $\mathrm{ORh}+$ blood group; platelets $\left(160,000 / \mathrm{mm}^{3}\right)$, alanine aminotransferase $(A L A T=33 \mathrm{IU} / \mathrm{L})$, aspartate aminotransferase $($ ASAT $=29 \mathrm{IU} / \mathrm{L})$, urea $(39 \mathrm{mg} \%)$ and creatinine $(0.85 \mathrm{mg} \%)$ were 


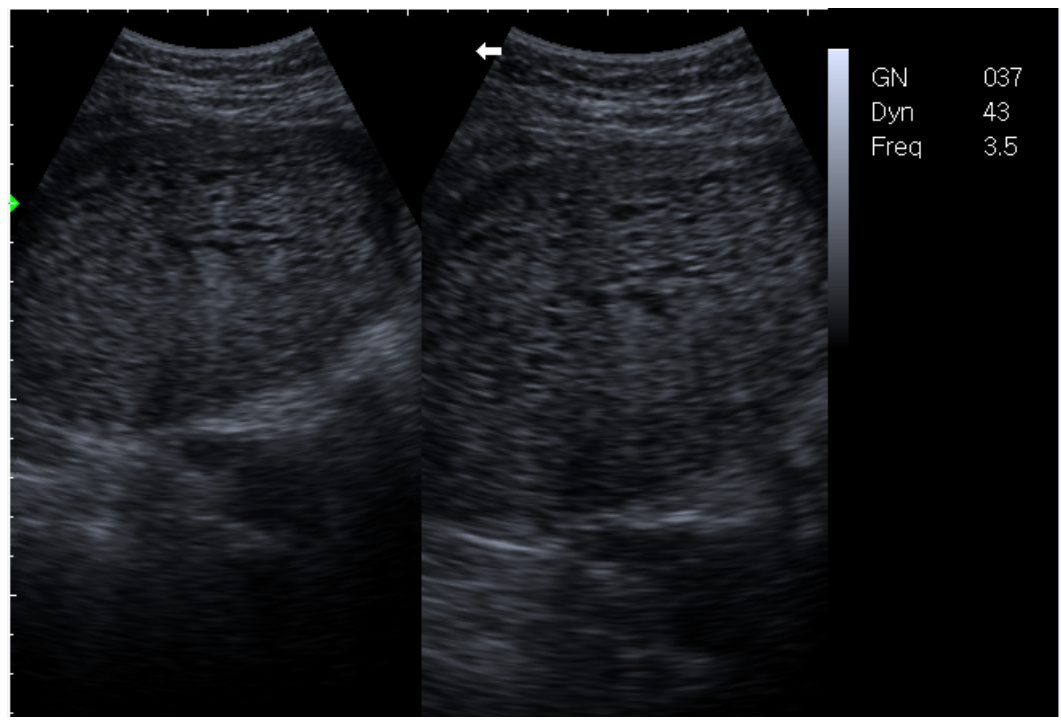

Figure 1. Ultrasound image showing characteristic honeycomb images filling the uterine cavity.

in the norms; albuminuria by dipstick was positive $(2+)$. We have been diagnosed with severe chronic hypertension with preeclampsia added according to the classification of the international society for the study of hypertension in pregnancy (ISSHG) [5].

After urgent evaluation of the pregnant woman with the internists and the emergency doctors, we administered antihypertensive therapy (intravenous hydralazine and labetalol in per os), and magnesium sulfate in prevention of eclamptic seizures. After information on the complications of a HM and the recommendations of her care, the pregnant woman consented to the termination of the pregnancy that we had indicated. Thus, we proceeded to the uterine evacuation under oxytocin infusion by manual ultrasound aspiration. The uterine contents were made of a vesicular mass corresponding to a CHM (Figure 2) confirmed by anatomopathological examination. In evolution, normalization of blood pressure was dramatic after uterine aspiration; the patient was on contraception for 3 months. The 12-month surveillance with serum beta-hCG monitoring was unremarkable. 2 years and 2 months later, she had gotten a pregnancy that had led to a term birth, without hypertensive disorders.

\section{Discussion}

We reported in this case the first documented case, in the north-eastern region of DRC, of preeclampsia on added on a complete hydatiform mole. We have therefore underlined the importance of ultrasonography and titration of $\beta$-hCG in the evaluation of any pregnant woman with early HBP before $20 \mathrm{WA}$; and the need for a multidisciplinary team to initiate appropriate care.

Indeed, HM and preeclampsia are two diseases of pregnancy each characterized by placental dysfunction which is an integral part of the pathological process. 


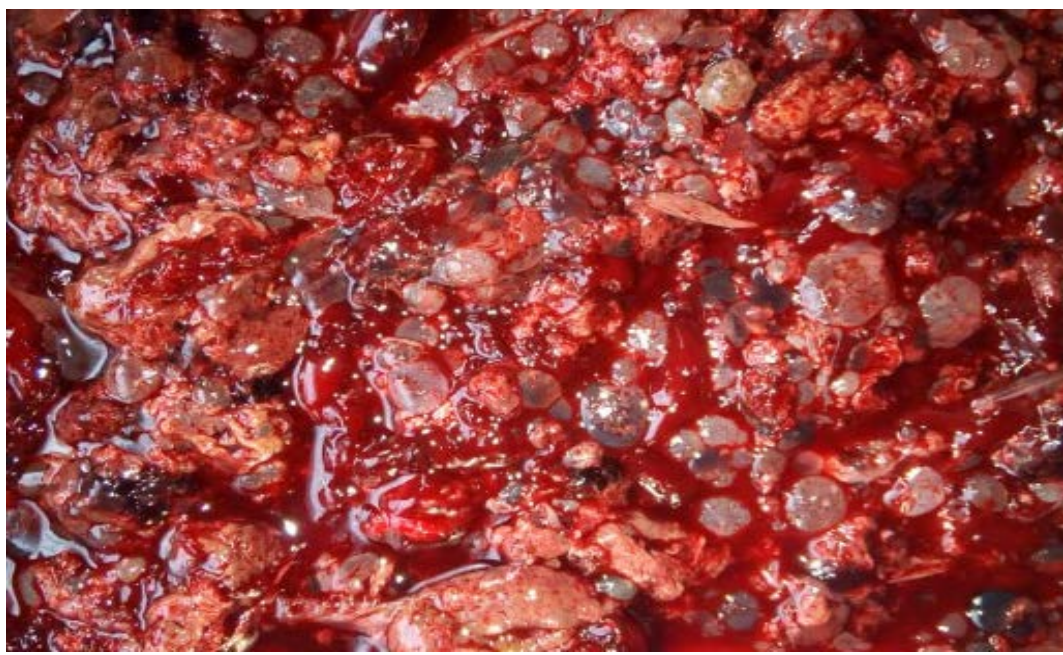

Figure 2. Design products after aspiration showing a vesicular mass without visible fetal traces.

HM is a relatively rare complication with an incidence that varies by region of the world and appears to be related to ethnic group, more prevalent in Southeast Asia ( 1 in 2 out of 1000 pregnancies in Japan and China) than in North America and Europe ( 0.57 to 1.1 out of 1000 pregnancies) [6] [7].

Its overall prevalence in the DRC is not well controlled. Mbala NL et al. [8] reported $0.13 \%$ of cases ( 1 in 783 pregnancies) in Kinshasa.

HM may be partial (PHM) or complete (CHM). In the PHM, characterized by an imbalance between the two genomes with persistence of a maternal genome and at least two sets of paternal chromosomes, the egg retains a recognizable placental form and an amniotic cavity with an embryo, or traces of embryo. In the CHM, associated with the presence or expression of the only paternal nuclear genome, hydropic degeneration is complete and no trace of embryo, amniotic cavity and even vascularization is observed [1].

CHM is the most common form and represents $80 \%$ of gestational trophoblastic diseases. Its risk factors are numerous, only some have been found in our patient. In fact, molar pregnancy is common at extreme ages of reproductive life [9]. This was the case in our patient aged 39 years. In addition, MHC is 10 times more common among women with blood group A whose partner is group $\mathrm{O}$; which is not the case in our case because the patient and her husband are blood group O. No history of molar pregnancy was found in our patient or in her family. Low socioeconomic status, nulliparity, race, malnutrition (protein, folate and carotene deficiency), consanguinity, environmental and genetic factors are other risk factors mentioned in the literature [10].

The diagnosis of CHM is classically suggested in a syndrome of first trimester metrorrhagia, exaggeration of sympathetic signs of pregnancy, increased uterine volume compared to gestational age and significant elevation of serum $\beta$-hCG. However, the diagnosis is now easy thanks to the ultrasound, especially when it comes to the CHM. This is the case of our patient. 
The metrorrhagias, found in $84 \%$ to $97 \%$ of the cases, are spontaneous, capricious, of increasing abundance; and are due to erosion of the uterine walls in the absence of placentation [11]. The exaggeration of sympathetic signs is a frequent occurrence of HM. It is due to hypersecretion of $\beta$-hCG. Indeed, hCG stimulates the corpus luteum to the production of estradiol and progesterone via their receptors luteinizing hormone-chorionic gonadotrophin receptor (LH-CGR) and plays a promotive role in the aromatization of steroids of the placenta [12]. Estrogens, like progesterone, are known inducers of nausea and vomiting.

It could also be that hCG, by stimulating LH-CGR like receptors, causes a duodenal and pancreatic ionic $\left(\mathrm{HCO}^{3-}\right.$ and $\left.\mathrm{K}^{+}\right)$flux. These secretions could in turn stimulate the mechanoreceptors present throughout the digestive tract, and trigger reflex vomiting by distension and activation of the gastrointestinal tract [13]. Finally, hCG is believed to be responsible for biological hyperthyroidism through thyrotropic action linked to a structural homology between hCG molecules and Thyroid Stimulating Hormon (TSH), as well as for their respective receptors explaining the action of hCG on TSH receptors [12] [14].

The patient can also complain of pelvic pain, present in $20 \%$ of cases and related to the presence of luteal cysts or the expulsion of vesicles [4]. Other signs may be related to anemia (physical asthenia, paleness and vertigo) as for our patient, or thyrotoxicosis syndrome (tachycardia, thermophobia, extremity tremor and weight loss).

On examination, the uterus is larger compared to the gestational age, abnormally soft with some shielding plates (sign of Anderodias); no sloshing or fetal relief. All these signs were recorded in our patient. Measurement of uterine height may vary from one examination to another (uterus accordion Jeanin).

Preeclampsia on added on CHBP (early preeclampsia), defined according to the ISSHG [5] by the occurrence of hypertension before 20 weeks of amenorrhea associated with proteinuria and edema, is a relatively common situation in type I triploidy with partial mole, as described in the paper Rijhsinghani et al. [3], a prevalence of $35 \%$ of cases. Its occurrence at an CHM is a less common situation. Alessandro et al. [4] had recorded it in $5 \%$ of cases.

In Nigeria, Igwebe AO and Eleje GU [15] had recorded preeclampsia in 9.7\% of all hydatiform moles.

Preeclampsia is a disease of hypotheses whose exact etiology remains uncertain. Long before, its occurrence in case of a HM made evoke the role of the uterine distension. This results in compression of the uterine arteries, to which is added a large placental volume to infuse, source of a poor uteroplacental perfusion, responsible for preeclampsia. This same mechanism would also be mentioned in case of hydramnios or multiple pregnancy.

However, it is currently shown that its clinical manifestations, namely HBP, proteinuria and characteristic renal injury (glomerular endotheliosis) are caused by an excess of anti-angiogenic proteins, particularly the soluble form of Fms-like tyrosine kinase 1 (sFlt1) in the maternal circulation after being overproduced in the placenta. This soluble factor sFlt1 antagonizes or decreases the 
free maternal circulating levels of angiogenic proteins such as vascular endothelial growth factor (VEGF) and free placental growth factor (PIGF) [16] [17]. $\mathrm{CHM}$, characterized by abnormal proliferation of syncytiotrophoblast and the hydropic degeneration of all chorionic villi, is often accompanied by hemoconcentration and alteration of vascular hemodynamics. Its association with early preeclampsia would suggest that this placentation abnormality is thought to be responsible for excessive production of endogenous antiangiogenic proteins, particularly the soluble form of Fms-like tyrosine kinase 1 (sFlt1) [16] [18].

The free circulating angiogenic factors VEGF and PlGF being essential for endothelial growth, differentiation and vascular integrity; and the decrease in vascular resistance and blood pressure [16].

The antagonistic effect or the decrease in their circulation rate by sFlt1 will explain the occurrence of early preeclampsia during a molar pregnancy. Aghajanian P. [19] think that preeclampsia in the first trimester or early second trimester is an exceptional finding in a normal but pathognomonic pregnancy of one hydatiform mole.

\section{Conclusions}

The clinical picture suggestive of HM seems to be known to any clinician, but does not define whether it was a CHM or a PHM. Thanks to the ultrasound examination, the initially unknown forms are finally recognized early by highlighting characteristic honeycomb or snowflake images.

However, the occurrence of early preeclampsia should suggest the diagnosis of $\mathrm{HM}$, if not a hyperhormonal pregnancy, especially if it is associated with the exaggeration of sympathetic signs in a pregnant woman with certain risk factors.

\section{Informed Consent}

The patient had consented to the publication of this case report accompanied by images.

\section{Authors's Contributions}

Doctor Bosenge Nguma JD contributed to the design of the manuscript. Doctors Labama NO and Nadi AJ contributed to the review of the literature. Professors Modia OA, Katenga BG and Komanda LE had analyzed the caseand corrected the final manuscript. All the authors contributed to the care of the patient, read and approved the final manuscript.

\section{Competing and Conflicting Interests}

The authors do not declare any conflict of interest.

\section{References}

[1] Boufettal, H., Coullin, P., Mahdaoui, S., Noun, M., Hermas, S. and Samouh, N. (2012) Les moles hydatiformes partielles au Maroc: Etude épidémiologique et 
clinique. EMHJ, 18, 755-761. https://doi.org/10.26719/2012.18.7.755

[2] van der Houwen, C., Schukken, T. and van Pampus, M. (2009) Transientearlypreeclampsia in Twinpregnancy with a Triploidfetus: A Case Report. Journal of Medical Case Reports, 3, 7311. https://doi.org/10.1186/1752-1947-3-7311

[3] Rijhsinghani, A., Yankowitz, J., Strauss, R.A., Kuller, R.A., Patil, S. and Williamson, R.A. (1997) Risk of Preeclampsia in Second-Trimester Triploid Pregnancies. Obstetrics \& Gynecology, 90, 884-888. https://doi.org/10.1016/S0029-7844(97)00540-1

[4] Cavaliere, A., Ermito, S., Dinatale, A. and Pedata, R. (2009) Management of Molar Pregnancy. Journal of Prenatal Medicine, 3, 15-17.

[5] Beillat, T. and Dreyfus, M. (2010) Hypertension artérielle et grossesse. Traité d'obstétrique, Elsevier Masson, 216-225. https://doi.org/10.1016/B978-2-294-07143-0.50029-9

[6] Lurain, J.R. and John, I. (2010) Gestational Trophoblastic Disease: Epidemiology, Pathology, Clinical Presentation and Diagnosis of Gestational Trophoblastic Disease, and Management of Hydatidiform Mole. American Journal of Obstetrics \& Gynecology, 203, 531-539. https://doi.org/10.1016/j.ajog.2010.06.073

[7] Lee, C., Smith, H.O. and Kim, S.J. (2009) Epidemiology. In: Hancock, B.W., Seckl, M.J., Berkowitz, R.S. and Cole, L.A., Eds., Gestational Trophoblastic Disease, 3rd Edition, ISSTD, McLean, 49-97.

[8] Mbala, N.L., Menayamu, N.D. and Mbanzulu, P.N. (2017) Aspects clinique et paraclinique de la grossesse molaire dans seux formations médicales de Kinshasa. Kis Med, 7, 281-290.

[9] Fouogue, T.J., Fouélifack, Y.F., Sando, Z., Mboudou, E.T. and Doh, A.S. (2011) Grossesse Môlaire et Difficultés de Prise en Charge en Milieu Rural: Illustration d'un Cas Clinique à l'Hôpital de District de Bogo (Extrême-Nord Cameroun). Clinics in Mother and Child Health, 8.

[10] Zulvayanti, Krisnadi, S.R. and Achadiyani (2017) Correlation between Three Pregnancy Characteristics (Age, Parity, $\beta$ hCG Level) and Immunoexpression on Complete Hydatidiform Mole. Open Access Library Journal, 4, e3634.

[11] Chu, M.M., Ma, Y., Tse, K.Y., Chan, K.K., et al. (2015) Cyclophosphamide, Hydroxyurea, Actinomycin d, Methotrexate, and Vincristine in the Treatment of Gestational Trophoblastic Neoplasia. International Journal of Gynecological Cancer, 25, 498-503. https://doi.org/10.1097/IGC.0000000000000383

[12] Anisodowleh, N., Farahnaz, K., Nasrin, J., Maryam, H. and Elaheh, B. (2016) Thyroid Hormone Levels and Its Relationship with Human Chorionic Gonadotropin in Patients with Hydatidiform Mole. Open Journal of Obstetricsand Gynecology, 6, 56-63. https://doi.org/10.4236/ojog.2016.61007

[13] Pansesar, N.S. and Poon, C.W. (1998) HCG: Its Pancreatic and Duodenal Receptors and in Vivo Electrolyte Secretion in Female Rats. American Journal of Physiology, 275, 1430-1436.

[14] Alemu., A., Terefe, B., Abebe, M. and Biadgo, B. (2016) Thyroid Hormone Dysfunction during Pregnancy: A Review. International Journal of Reproductive Biomedicine, 14, 677-686.

[15] Igwegbe, A.O. and Eleje, G.U. (2013) Hydatidiform Mole: A Review of Management Outcomes in a Tertiaryhospital in South-East Nigeria. Annals of Medical and Health Science Research, 3, 210-214. https://doi.org/10.4103/2141-9248.113664

[16] Kanter, D., Marshall, D.L., Eileen Wang, R., Borromeo, E., Ananthkarumanchi, S. and Stillman, I.E. (2010) Angiogenic Dysfunction in Molar Pregnancy. American 
Journal of Obstetrics \& Gynecology, 202, 184e1-184.e5.

[17] Lam, C., Lim, K.H. and Karumanchi, S.A. (2005) Circulating Angiogenic Factors in the Pathogenesis and Prediction of Preeclampsia. Hypertension, 46, 1077-1085. https://doi.org/10.1161/01.HYP.0000187899.34379.b0

[18] Amber, D., Brandi, J., Niles, I., Nneoma, N. and Vanessa, M. (2015) Atypical HELLP Syndrome in a Hydatidiform Molar Pregnancy: A Case Report. Medical Journal of Obstetrics and Gynecology, 3, 1064-1066.

[19] Aghajanian, P. (2013) Gestationaltrophoblasticdisease. In: Igwegbe, A.O. and Eleje, G.U., Eds., Hydatidiform Mole: A Review of Management Outcomes in a Tertiaryhospital in South-East Nigeria. Annals of Medical and Health Science Research, 3, 210-214. https://doi.org/10.4103/2141-9248.113664 